\title{
Muerte, vida y obra de monseñor Isaías Duarte Cancino: un caso de aplicación de la metodología del relato necrobiográfico
}

\section{Dead, life and work of monsignor Isaías Duarte Cancino: A case of application of the methodology of the necrobiographical report}

Wilson Martínez Guaca*

\section{Resumen}

Este artículo presenta la muerte, la vida y la obra de Monseñor Isaías Duarte Cancino, como un caso de aplicación de la ruta metodológica denominada relato necrobiográfico o necrobiografía, una propuesta de reconstrucción de relatos biográficos relacionados con personajes fallecidos, desarrollado en la Fundación Universitaria Católica Lumen Gentium. El artículo es producto de una investigación en la que se contrastaron los géneros biográficos existentes con las prácticas de historiadores y periodistas, y luego se adecuaron a un tipo de escrito periodístico. El artículo muestra también la conceptualización y la ruta metodológica de la necrobiografía o relato necrobiográfico.

Palabras claves: géneros biográficos, Monseñor Isaías Duarte, necrobiografía, reportaje necrobiográfico.

\section{Abstract}

This article presents the death, life and work of Monsignor Isaias Duarte Cancino, as a case of application of the methodological route called necrobiographical report or necrobiography, a proposal of reconstruction of biographical facts related to deceased characters, developed in the Fundación Universitaria Católica Lumen Gentium. The article is the result of an investigation in which existing biographical genres were contrasted with the practices of historians and journalists and, then, adapted to a type of journalistic writing. The article also shows the conceptualization and the methodological route of necrobiography or necrobiographical story.

Keywords: biographical genres, Monsignor Isaías Duarte, necrobiography, necrobiographic report.

\footnotetext{
* Comunicador Social -Periodista. Licenciado en Lingüística y Literatura. Magister en Estudios Políticos. Candidato a Doctor en Comunicación, Universidad Nacional de La Plata - UNLP. Argentina.

Investigador. Grupo de investigación U-MANOS. Correo electrónico: wmartinez@unicatolica.edu.co

** Comunicador Social-Periodista. Magister en Salud Pública. Unicatólica. Investigador. Grupo de investigación U-MANOS. Correo electrónico: jrios@unicatolica.edu.co
} 


\section{Introducción}

A lo largo de la construcción teórica y metodológica de los géneros y tipos de textos literarios y/o periodísticos, se han definido a varios que se agrupan en lo que algunos identifican como géneros biográficos, entre los cuales encontramos la biografía, definida como un:

(...) género histórico-literario específico en el que un investigador «reconstruye» una trayectoria individual sobre la base de documentación preferentemente escrita y con el auxilio eventual de fuentes orales en el caso que se trate de la biografía de una persona contemporánea (Pujadas, 2000, p. 136).

También encontramos la autobiografía, que para algunos autores es clave en la elaboración de la biografía, como quiera que esta"es un juego de intersubjetividades que emerge esencialmente de la persona y de su testimonio, ya sea oral o escrito" (Sanz Hernández, 2005, p. 99 ). Otro escrito periodístico con elementos biográficos es la semblanza, entendida como"un reportaje acerca de una persona real con un tema de interes humano. Su objetivo es resaltar la individualidad de una persona o colocar en un marco general su valor simbolico social" (Badillo, 2011); generalmente este tipo de escrito periodístico se utiliza para alabar las cualidades personales o profesionales de alguien. Dentro de esta misma línea se encuentra también el perfil, que para autores como Jon Lee Anderson, es el arte de pintar con palabras a una persona, sin una linealidad ni una metodología (Restrepo, 2011). Finalmente, con un sentido también biográfico, pero limitado a los momentos del paso de la vida a la muerte, está la necrológica, donde el estilo que adopta el periodista es el responsable de dejar en la memoria, los momentos más significativos para que estos no sean fácilmente olvidados (López Hidalgo, 1999).

Otros géneros o textos utilizados para la elaboración de relatos biográficos, no solo en el periodismo, sino también en otras disciplinas, son la historia de vida, el relato en general y los relatos de vida. La historia de vida puede definirse como un texto de tipo inductivo, holístico y subjetivo, pues involucra más al investigador con el protagonista. Inductivo, porque parte de la observación que se hace del entrevistado; holístico, porque configura una visión general a través de la psicología del ciclo vital del protagonista; y subjetivo, porque procede de la experiencia de vida del sujeto (Martín García, 1995). Sobre este mismo escrito, López Hidalgo (2002) indica que "una historia de vida es mucho más que una biografía o en todo caso no deja de ser algo distinto" (p.2), señalando que el método para elaborar la historia de vida se basa en la entrevista periodística. El relato, por su parte, es un recurso que todo periodista usa para contar e informar sobre la realidad, ya que se aplica a todas las narrativas periodísticas en sus diversas modalidades o clasificaciones: noticia, reportaje, crónica, entrevista (Garza, 2002), mientras que los relatos de vida articulan significados subjetivos de personajes con experiencias y prácticas sociales (Cornejo, Mendoza y Rojas, 2008).

A pesar de toda esta cantidad de tipos o géneros periodísticos, no hay ninguno con la condición específica de la muerte, por lo que se hace necesario la identificación y definición de uno nuevo, que además cuente con una ruta metodológica que señale el paso a paso para su proceso de elaboración.

Lo que se propone con este artículo es, en primer lugar, mostrar la teoría y la ruta metodológíca denominada relato necrobiográfico o necrobiografía, que tiene como eje temático central la muerte, pero que de igual manera recoge la vida y la obra o legado del personaje fallecido, y en segundo lugar, aplicar esta metodología al caso de Monseñor Isaías Duarte Cancino.

La visibilización de la muerte (su asesinato), la vida y el legado de este alto jerarca de la iglesia católica colombiana toma especial relevancia teniendo en cuenta que todas las publicaciones relacionadas con ello están fragmentadas en informes de prensa o condensadas en algunos libros que, por ser elaborados por religiosos, le dan un tratamiento desde la visión únicamente bíblica, o propia de la iglesia.

En consecuencia a lo anteriormente expuesto, este artículo desarrolla los siguientes asuntos: presentación de la metodología para la reconstrucción de relatos biográficos sobre personaje fallecidos y la aplicación de esta metodología al caso de Monseñor Isaías Duarte Cancino. 


\section{Métodos y materiales}

Para identificar una ruta metodológica para la reconstrucción de relatos biográficos de personajes fallecidos, fue necesario utilizar un método cualitativo, histórico- hermenéutico, que permitió interpretar y comprender una realidad social en el contexto determinado de la práctica periodística.

En lo relacionado con la ruta metodológica, se identificaron los diferentes géneros o modalidades de escritos periodísticos conocidos. Una vez identificados estos géneros, se seleccionaron, teniendo en cuenta su aplicabilidad al caso de un relato biográfico sobre un personaje fallecido. Los géneros seleccionados fueron: historia de vida, relato, necrológica, semblanza, perfil y biografía; de cada uno de estos se tomó una muestra de tres artículos o publicaciones, de diferente autor, y se analizaron desde tres categorías temáticas: definición, metodología y organización del documento final. Este proceso arrojó la unificación conceptual y metodológica por género. Los géneros, así sistematizados, se unieron en dos grandes grupo de tres, que al triangularse, sobre la base de las mimas categorías, arrojaron dos resultados, los cuales al fusionarse o cruzarse arrojaron un primer gran resultado sobre conceptualización, metodología y organización.

Una segunda parte de este proceso se hizo mediante la aproximación a un grupo de historiadores y periodistas locales, a quienes se les preguntó sobre su conceptualización, su paso a paso o realización y la organización de un texto escrito, relacionado con un relato biográfico de un personaje fallecido. Con estas fuentes orales, se realizó también una triangulación, cuyos resultados se fusionaron por profesión y luego entre ellas para obtener un segundo gran resultado sobre la ruta metodológica para abordar relatos de personajes fallecidos. Al cruzar los resultados de las fuentes documentales y de las fuentes orales, se obtuvo un resultado final, que permitió una conceptualización, una metodología y una guía de organización textual.

El proceso de indagación, sistematización y análisis de esta primera fase de la investigación se realizó en la ciudad de Cali, Valle del Cauca, Colombia, utilizando como técnicas e instrumentos para la recolección de datos, el análisis do- cumental, que arrojó unas fichas de registro de datos y la entrevista, que también se sistematizó mediante fichas de recolección de datos.

En lo referente a la validación del género y la metodología planteados, se procedió a otro proceso de investigación, que también abarcó fuentes documentales y orales, relacionadas con Monseñor Isaías Duarte Cancino, y que podríamos ubicar también en el enfoque cualitativo, como un estudio descriptivo y un diseño biográfico o narrativo.

Para ello se aplicó, paso a paso, la ruta metodológica propuesta, centrándose la indagación, tanto documental como oral, en el Valle del Cauca, Norte de Santander, Santander y el Urabá antioqueño-chocoano; la recolección de datos se orientó a publicaciones de medios, escritos del personaje, bancos documentales de los estamentos religiosos y gubernamentales, y entrevistas a familiares, compañeros de apostolado, amigos, autoridades, feligreses, beneficiarios y personas que de una $u$ otra forma tuvieron algún contacto con Monseñor Duarte Cancino. Toda esta información se sistematizó y se categorizó en los tres grandes ejes temáticos: muerte, vida y legado. Las técnicas utilizadas para la recolección de datos en esta fase también fueron el análisis documental y la entrevista.

La totalidad del proceso de recolección de datos, tanto documentales como orales, se hizo valorando la validez, seriedad y objetividad de los medios consultados y de los personajes entrevistados, contrastando las posiciones encontradas y profundizando, con la debida autorización, en aspectos inéditos o desconocidos.

Al plantearse la escritura del texto de validación, se encontró que si bien la investigación había arrojado unas guías generales para su organización y líneas de tiempo, estas debían adaptarse a los modelos de escritos periodísticos existentes, por lo cual se hizo necesario otro análisis documental sobre la estructura textual, o de forma, de la noticia, el reportaje, la crónica, el artículo y el editorial. El resultado de este estudio arrojó que el tipo de escrito periodístico más adecuado para materializar el relato necrobiográfico o necrobiografía era el reportaje, en la modalidad de reportaje en profundidad, lo cual permite elaborar dos opciones: un 
reportaje necrobiográfico y una necrobiografía o relato necrobiográfico.

La diferencia entre el reportaje necrobiográfico y la necrobiografía es que el primero es una especie de síntesis del segundo, es decir, que en un solo texto se presenta la muerte, la vida y el legado de un personaje fallecido, mientras que el segundo es una publicación por capítulos, en la que cada capítulo corresponde a cada uno de los ejes temáticos, es decir, un capítulo de la muerte, otro de la vida, y otro del legado, y en la que, ademá,s cada capítulo es presentado con la estructura del reportaje.

\section{La necrografía o relato necrobiográfico}

La necrobiografía, o relato necrológico, es entendido como un relato biográfico que hace énfasis en los aspectos relacionados con la muerte del personaje. A diferencia de la biografía o el perfil, obliga a relatar este momento de manera obligatoria y no opcional. En consecuencia, se puede definir como "un género periodístico que reconstruye la muerte, el legado y la trayectoria de vida de un personaje, partiendo y teniendo como eje su deceso y con base en la consulta, de fuentes orales y documentales" ${ }^{\prime 3}$. Como todo producto periodístico, la necrobiografía o relato necrobiográfico, tiene tres momentos para su realización: preproducción, producción y posproducción.

\section{Preproducción}

- Planteamiento de la investigación (problema, pregunta, objetivos, etc.).

- Relación de documentos necesarios para la investigación.

- Ordenamiento de la información cronológica y temáticamente y ubicarlos por eje temático.

- Recopilación documental relacionada con el personaje fallecido: lo escrito y lo que exista en audio o en video sobre este.

- Revisión de autobiografías, libros, publicaciones, creaciones artísticas, documentales, películas u otros trabajos realizados por el personaje fallecido.

- Revisión de correspondencia que haya dejado el personaje.

\footnotetext{
3 Esta es la definición a la que se llegó sobre necrobiografía o relato necrobiográfico, luego del trabajo de investigación titulado Abordaje Metodológico para la reconstrucción de relatos biográficos de personajes fallecidos. Caso Monseñor Isaías Duarte Cancino, realizado por los autories del presente artículo.
}

- Revisión de las reseñas de prensa del personaje fallecido.

- Recopilación de sus pronunciamientos y/o denuncias.

- Conocimiento de los objetos, fotos e imágenes que dejó el personaje.

- Estudio de cada fuente documental en profundidad (sistematización).

- Relación de personas a entrevistar, que aporten al trabajo planteado: personas del universo familiar o social del personaje fallecido, que permitan calibrar y dar perspectiva a la narración principal. Personas del universo laboral del personaje fallecido o que de alguna manera hayan tenido que ver con él y con sus actividades desarrolladas.

- Fase de contactos, lógica de los encuentros, consentimiento de los participantes, presentación de los investigadores.

- Procedimiento de las entrevistas (número de encuentros, ritmo y duración de las entrevistas).

- Ajustar el estilo oral del informante para que sea aceptable por este.

- Estudio de cada fuente viva en profundidad (sistematización).

Temáticas para investigar en los documentos y las entrevistas: lugar, fecha y causa de la muerte. Contextualización de su muerte; lo qué hacía en sus últimos días de vida. Sentimientos por su desaparición. Establecer cada etapa de su vida: nacimiento, familia, capacitación, actividades, etc. Valores y principios que movieron su vida y cómo llegó a ellos. Contexto en el que vivió. Respuestas que dio a las situaciones de tiempo y su contexto. Obras y legados materiales e inmateriales;. Mirada que se plantea en el documento o por parte del entrevistado sobre el personaje fallecido (aciertos o desaciertos). Momentos más importantes de su vida. Proyecciones que plantean los documentos o los entrevistados relacionados con el personaje fallecido.

\section{Producción}

Organización flexible del texto sin tiempos específicos, es un ir y venir, donde la información se maneja en una multiplicidad temporal debido a lo cambiante de los entornos; debido a esta circunstancia, la estructura del relato se asimila a la del reportaje (lead, contexto, cuerpo, cierre). Los relatos responden al tratamiento de una temática o ejes temáticos, porque es la historia 
quien cuenta una realidad. La narración se hace en torno a tres grandes categorías o ejes: muerte o necrológica, biografía y relato.

La categoría necrológica es la que narra las situaciones relacionadas con el fallecimiento del personaje: la muerte (circunstancias de su deceso), causas de su muerte, el personaje en los días anteriores a su muerte, hechos y sentimientos como efectos de su muerte, los días posteriores a su muerte y las experiencias e imaginarios después de la muerte del personaje.

La categoría biográfica abarca la vida familiar del personaje (nacimiento, niñez, juventud, edad adulta, mayoría de edad); la capacitación o estudios del personaje (primaria, secundaria, profesional); la vida laboral del personaje, la personalidad (carácter del personaje, formas de reaccionar ante las diversas situaciones, dificultades y logros relacionados con su personalidad); vida política del personaje (posición ideológica, evolución de su pensamiento, acción política); vida socio-comunitaria del personaje (intervenciones en las comunidades donde vivió); logros y dificultades de su intervención socio-comunitaria; los momentos cumbres de su vida; los peores momentos de su vida, valores y principios que movieron la vida del personaje; respuesta a las situaciones de su época, anécdotas.

La categoría legado contempla el legado (material e inmaterial) del personaje, hechos actuales y la relación con el pensamiento y/o las acciones del fallecido, el aporte este a su familia y a la sociedad, y la permanencia y perpetuación de su obra o su legado.

\section{Posproducción}

Revisión de forma y estilo y publicación.

\section{Caso de aplicación: Muerte, vida y obra de Monseñor Isaías Duarte Cancino}

El sonido de los disparos se confundió con los voladores y con la algarabía de la fiesta colectiva del matrimonio; la muerte llegó de repente para apagar la palabra de vida y de paz que, solo unos instantes atrás, había logrado iluminar la vida de centenares de parejas.

Luego de celebrar una ceremonia litúrgica fue asesinado, en marzo de 2002, en la ciudad de Cali, Mon- señor Isaías Duarte Cancino, arzobispo local, quien se había destacado por su fuerte compromiso con las comunidades. Monseñor Duarte Cancino, era oriundo del departamento de Santander y su obra pastoral se había centrado especialmente en la región de Urabá y en la capital vallecaucana, donde realizó innumerables obras materiales e inmateriales.

El asesinato de Monseñor Isaías Duarte Cancino ocurrió la noche del 16 de marzo de 2002, en momentos en que salía del templo El Buen Pastor, donde había dirigido una misa en la que dio la bendición a 104 parejas que se unieron en matrimonio (De La Vega, Comunicación personal, 15 de septiembre de 2016). El templo está ubicado en el barrio Ricardo Balcázar, Distrito de Agua Blanca, al centro oriente de Cali.

Monseñor Isaías Duarte Cancino había nacido en San Gil, departamento de Santander el 15 de febrero de 1939; sus padres fueron Crisanto Duarte y Elisa Cancino Arenas, y él era el menor de siete hermanos (Fundación Isaías Duarte Cancino, 2016). Realizó estudios de primaria en la Escuela San Luís, de su pueblo natal. Luego hizo su bachillerato en el Colegio Santander de Bucaramanga, para pasar posteriormente al Seminario Mayor de Pamplona, Norte de Santander (Duarte Cancino, Comunicación personal, 8 de junio de 2017). En Pamplona realizó tres años de Filosofía y un año de Teología, pero luego viajó a Roma a terminar la Teología en la Universidad Gregoriana (Gutiérrez Mendoza, Comunicación personal, 8 de junio de 2017), estableciéndose en las residencias del Colegio Pio Latinoamericano, ubicado en la vía Aurelia, donde se destacó por su liderazgo espiritual, hasta el punto que sus compañeros lo llamaban "excelencia" (Alarcón, Comunicación personal, 5 de junio de 2017). Luego de cuatro años de estudio, obtendría el grado académico de Licenciado en Teología. Durante la Segunda Sesión del Concilio Vaticano II, el 1 de Diciembre de 1963, fue ordenado sacerdote al servicio de Dios y de los hombres, por su Obispo, Monseñor Héctor Rueda Hernández (Fundación Isaías Duarte Cancino, 2016). Cuando recibió los votos como sacerdote solo tenía 24 años de edad. De acuerdo con Jaimes:

(...) parece raro que se hubiera ordenado allá en Roma y que lo hubiera ordenado Monseñor Rueda, dado que él era arzobispo de aquí de Bucaramanga, pero entonces eso sucedió durante el tiempo del Concilio Vatica- 
no II y como Monseñor Rueda tenía que participar en el Concilio, entonces él estaba allá en ese tiempo y se ordenó allá (Jaimes, Comunicación personal, 6 de septiembre de 2016).

El ataque que terminó con la vida de Monseñor Isaías Duarte Cancino, fue perpetrado por dos jóvenes sicarios, hacia las 8:15 de la noche de ese 16 de marzo de 2002, y su muerte ocurrió en los momentos en que era conducido al Hospital Carlos Holmes Trujillo (El País Cali, 17 de marzo de 2002), ubicado en el barrio El Poblado II a unas quince cuadras del lugar de los hechos. El prelado"tenía lesiones en el brazo, en una mano y un impacto en un costado, el derecho, que al parecer fue el que le causó la muerte" (Comunicaciones Caracol Radio, 16 de marzo de 2017).

A su muerte, Monseñor Isaías Duarte Cancino dejó en enorme legado inmaterial y material que benefició a las comunidades donde desarrolló su acción pastoral: departamento de Santander, El Urabá antioqueño-chocoano, la ciudad de Cali y el departamento del Valle del Cauca. Como sacerdote en Bucaramanga, Girón, Málaga y otros municipios de Santander, se preocupó por el fortalecimiento de la fe cristiana en su feligresía, por el apoyo a las diferentes organizaciones de base de la iglesia y por la fundación de colegios y centros de aprendizaje laboral (Jaimes, Comunicación personal, 6 de septiembre de 2016); también por la fundación de ancianatos y la recuperación de templos. De acuerdo con Romero, "como obispo auxiliar de Bucaramanga, una de sus mayores acciones fue llevar a esta ciudad una sede de la Universidad Pontificia Bolivariana" (Romero Cifuentes, Comunicación personal, 7 de septiembre de 2016).

El asesinato de Monseñor Duarte Cancino causó un profundo impacto en toda la sociedad colombiana, que asistía impávida al recrudecimiento de la guerra y a lo que parecía la entronización de los más oscuros sectores de la sociedad; se trató de"un complot para callar una conciencia moral, un crimen de lesa humanidad en el que concluyeron fuerzas oscuras y por eso hay mucha gente interesada en que no se sepa la verdad" (de la Vega, Comunicación personal, 15 de septiembre de 2016). Para regiones como el Urabá y el Valle del Cauca, donde ejerció su acción pastoral y social, constituyó la destrucción de la luz, del líder, que siempre irradiaba la esperanza de un país mejor, generando "mucho dolor, mucha tristeza por la pér- dida tan grande de una persona de un corazón tan gigante, de un corazón tan lleno de amor, de un corazón que solo quería la justicia en un país" (Echavarría Zapata, A. C., Comunicación personal, 6 de septiembre de 2016).

A finales de 1964 regresa a Bucaramanga en medio de la expectativa de toda la Arquidiócesis, pues era el primer seminarista de su jurisdicción que había terminado sus estudios en Roma. Entre las primeras actividades que realizó en sus inicios de su vida sacerdotal se encuentran: Vicario Cooperador de la Catedral de Bucaramanga, profesor en los seminarios arquidiocesanos de Pamplona y Floridablanca, párroco en la parroquias del Espíritu Santo, de la catedral de la Sagrada Familia de Bucaramanga y en los municipios santandereanos de Girón, García Rovira y Málaga, vicario de la Pastoral Arquidiocesana y finalmente Obispo auxiliar de Bucaramanga, cargo que desempeño entre 1985 y 1988, cuando fue nombrado como el primer Obispo de la apenas creada Diócesis de Apartadó, con jurisdicción en la región del Urabá, que abarca territorios de los departamentos de Antioquia y Chocó (Fundación Isaías Duarte Cancino, 2016). En la diócesis de Apartadó se desempeñó como obispo entre 1988 y 1995; en el año 1995 fue nombrado como Arzobispo de Cali, donde permaneció hasta la fecha de su asesinato en 2002.

En los días anteriores a su asesinato, se había convertido en el principal oponente al proceso de paz que adelantaba el entonces presidente Andrés Pastrana con la guerrilla de las FARC y que se terminaría abruptamente un mes antes de su sacrificio (Paz, G., Comunicación personal, 28 de agosto de 2016). Una semana antes de su asesinato, había entregado declaraciones a la prensa y se había expresado desde los altares denunciando la infiltración de dineros del narcotráfico en la campaña política regional que por esos días estaba en pleno furor: "En Cali denunció, días antes de las elecciones para el Congreso, del domingo pasado, que algunas campañas estaban infiltradas por el narcotráfico. Sobre esta denuncia el presidente Andrés Pastrana le pidió al religioso que identificara a los supuestos responsables de recibir dineros ilícitos y que si no lo hacía era como tirar la piedra y esconder la mano" (Nulivalue, 2002, p. 3).

Como obispo de la Diócesis de Apartadó, creó toda la estructura material de esta sede episcopal: catedral y 
sede de la diócesis; fundó el Seminario Nuestra Señora del Antiguo Darién y el Centro de Formación de Laicos; creó el Centro Misionero en Carepa y lo encomendó a las Hermanas Teresitas Misioneras, también el Monasterio de la Visitación; de ese tiempo también surgen los Colegios Diocesanos, de estos aún funciona el Colegio Nuestra Señora del Carmen de Turbo, bajo dirección de las Hermanitas Carmelitas, el Colegio Madre Laura de Chigorodó y el Colegio Juan Pablo II de Apartadó; la gran mayoría de las parroquias, si no venían con su existencia, fueron obra de Monseñor Isaías (Torres, H. A., Comunicación personal, 9 de septiembre de 2016). En esta región Monseñor Duarte le dio la identidad a la diócesis y llevó el mensaje del evangelio de Jesús a todos los rincones del territorio, propiciando el diálogo con los grupos armados de la zona y convirtiéndose en el eje central de la defensa de los derechos humanos.

Se movió desde lo social y nos enseñó cómo se dialoga con los grupos al margen de la ley, cómo se hace acompañamiento a esas comunidades, cómo se defiende la vida de las personas. Yo creo que él tuvo actos de arrebato para salvar muchas vidas, y lo más seguro es que tuvo contacto directo con los jefes de estas agrupaciones, no tanto para sacar partido de sus amistades, sino para 'halar la oreja'y llamar la atención cuando se enteraba de que alguien había sido secuestrado, iban a asesinar o desalojar de su espacio (Torres, H. A., Comunicación personal, 9 de septiembre de 2016).

Durante la mañana de ese 16 de marzo, Monseñor Isaías presidió, en la Fundación Universitaria Lumen Gentium, el centro educativo de educación superior creado por él, un evento denominado Foro por la paz: conflicto y postconflicto colombiano, donde sus palabras estuvieron orientadas a la esperanza de la paz para el país y a la necesidad de luchar por ella desde todos los campos, especialmente desde la educación: "Él hablo de la necesidad de la paz, pero no de una paz romántica ni quimérica, él hablo de una paz con reivindicación de la dignidad del ser humano, él creía fundamentalmente que la solución estaba en la educación, el creía que educando a un niño se salvaba a un hombre de la ilegalidad, de las armas y de la violencia" (Barona, M., Comunicación personal, 30 de agosto de 2016).

Durante la noche, luego de su asesinato se presentó un inexplicable apagón de la energía eléctrica que dejó a oscuras a medio país: "a mí me dio mucho miedo ese apagón y cuando llegué a la casa donde vivía Monseñor en Santa Mónica, la gente había encendido velas en el antejardín"(Barona, 2016, p. 2); "Y en esa noche triste, a plena medianoche, cuando todo era desconcierto y pregunta sin respuesta, empezó una tempestad con truenos y relámpagos y la energía se fue en Cali" (Montoya, 2012, p. 290).

Hombre de personalidad recia, de mal genio, según sus más cercanos colaboradores, podía entrar en ira en un momento determinado, pero asimismo era capaz de reconocer su debilidad y de pedir perdón a quien hubiera afectado con su actitud (Paternina, G., Comunicación personal, septiembre 6, 2016). Otro de los aspectos destacados de su personalidad era su sinceridad y forma directa de decir lo que sentía y lo que pensaba, sin medir ningún tipo de consecuencias, era una hombre "frentero", "sin miedo", aseguran quienes lo conocieron y compartieron con él,"era un hombre de temperamento fuerte, pero con un corazón bondadoso, sencillo, fácilmente él cuando veía que se equivocaba pedía perdón y mantenía siempre unas relaciones muy fraternas con las comunidades, con los sacerdotes" (Rueda, A., Comunicación personal, 6 de septiembre de 2016).

Luego de los procesos de rigor por parte de las autoridades, el cadáver de Monseñor permaneció en cámara ardiente en la catedral de Cali, durante los días domingo 17, lunes 18 y martes 19, cuando se cumplieron sus exequias en la misma catedral, a un lado del altar mayor. Durante estos días, centenares de personas desfilaron para darle el último adiós, pero quienes estuvieron junto a su cadáver durante todo el tiempo que permaneció en velación fueron los afectados por los secuestros del Km.18 y de la iglesia La María.

Los primeros en llegar a la catedral de Cali, donde se celebra el velatorio del arzobispo asesinado, fueron los afectados por los secuestros masivos realizados por el ELN en esa ciudad (El País, 2002). Portando banderas de Colombia, los familiares de los secuestrados y plagiados, rezaban y cantaban la estrofa:"Tú eres mi hermano del alma, realmente mi amigo" (El Tiempo, 2002). “Nos sentimos huérfanos; él era nuestra mano derecha, dijo acongojada una mujer de las que vivió el drama de la iglesia de la María" (El País, 2002). Guillermo Zúñiga, secuestrado junto con su esposa Roxana Ramírez, dijo que se segó la vida de un hombre que lo único que hizo fue trabajar por los 
pobres y los secuestrados de este país. Era una voz de aliento. En la montaña lo escuchábamos por radio, nos ayudó espiritualmente a sobrevivir, dijo Zúñiga (El Tiempo, 2002).

Para quienes conocieron a Monseñor Isaías Duarte, su pensamiento, su trabajo en educación, derechos humanos e intermediación con los grupos alzados en armas han sido una de las fuentes donde se nutrió el actual proceso de paz. Gracias a su inquebrantable tesón fue posible la desmovilización del EPL (Ejército Popular de Liberación) en el año 1991, y su voz y su pensamiento siempre se hizo sentir en los campos y ciudades del Urabá y del Valle del Cauca, y si “estuviera vivo seguramente que hubiera sido especial protagonista del actual proceso" (Villegas, G., Comunicación personal, 30 de septiembre de 2016).

Durante la misa de ese domingo 17 de marzo en Roma, en la Plaza de San Pedro, el Papa Juan Pablo II, expresó que el arzobispo de Cali "pagó un precio muy alto por su enérgica defensa de la vida humana y su firme oposición a toda clase de violencia" (BBC Mundo, 18 de marzo de 2002). Desde todos los puntos de Latinoamérica se recibieron condolencias y solidaridad, "fue un pastor valiente y fiel al servicio de la Iglesia, por lo que rechazo este acto de violencia contra un Arzobispo que solo quiso ayudar a encontrar caminos de paz en su país. Creo que el valor de la vida debe ser siempre rescatado, y Dios quiera que esto sea el comienzo del fin para la violencia en Colombia", expresó en su comunicación a la Conferencia Episcopal colombiana, el Cardenal Juan Luis Cipriani, Arzobispo de Lima y Primado del Perú, y así como él, desde toda la jerarquía eclesiástica del mundo se recibieron mensajes.

Desde su posición ideológica religiosa, primero como sacerdote, luego como Obispo, y finalmente como Arzobispo, Monseñor Isaías basaba toda su fuerza espiritual, su extraordinaria fe y su profunda confianza en el ser humano, en el pensamiento de san Irineo de Lyón (Domínguez, J., Comunicación personal, 10 de septiembre de 2016); "la gloria de Dios es el hombre viviente, todo lo que haga que el hombre viva y viva dignamente en su condición de persona y de hijo de Dios, es lo que de manera especial da gloria al Señor" (Isaza, G., Comunicación personal, 15 de septiembre de 2016).
Las exequias de Monseñor Isaías se cumplieron el martes 19 de marzo, en la Iglesia Catedral de San Pedro, ubicada en pleno corazón de la ciudad de Cali, hasta donde llegaron miles de personas, entre feligreses y autoridades eclesiásticas, militares y políticas, encabezadas por el propio presidente de la República Andrés Pastrana Arango, los diferentes candidatos a la presidencia y decenas de congresistas. La ceremonia fue concelebrada por el Nuncio Apostólico Beniamino Stella, el cardenal y antecesor de Monseñor Isaías en la arquidiócesis de Cali, Pedro Rubiano Sáenz, 90 obispos y más de un centenar de sacerdotes procedentes de todo el país y de algunos países de Latinoamérica (Revista Vitral, 2002). Uno de los hechos que llamó la atención fue la tremenda rechifla que se escuchó en la intervención del presidente Pastrana: "Algunos de los presentes abuchearon a Pastrana gritando «justicia, justicia», o «que se vaya», lo que obligó al presidente a abreviar su discurso (Zenit, 2002). Con la promesa de no descansar hasta hacer justicia, el presidente intentó calmar los ánimos, pero la muchedumbre acentúo sus abucheos mientras levantaron carteles recriminando la acción del mandatario quien días antes había cuestionado a Monseñor Isaías por hablar de la presencia de dineros de narcotráfico en las campañas políticas: "además de la rechifla, en medio de la plaza varios carteles se elevaban desafiantes con la leyenda:"Presidente, usted puso contra la pared a Monseñor" (El Tiempo, 2002).

Como arzobispo de la arquidiócesis de Cali, en sus siete años de orientación desarrolló una impresionante labor en la creación de colegios, parroquias y una universidad, además de todo tipo de centros de capacitación tanto para los sacerdotes miembros de la arquidiócesis, como para los grupos de apoyo y otros sectores de la población sin posibilidad de acceso a los centros formativos. Entre las obras relacionadas con la educación, creadas e impulsadas por Monseñor Isaías Duarte Cancino, están: creación de 19 parroquias, profesionalización de mujeres cabeza de familia (diseño y confección, manejo de máquinas industriales y desarrollo humano), también "creó la Fundación Universitaria Católica Lumen Gentium y 9 colegios arquidiocesanos y la Comisión de Vida, Justicia y Paz" (Oficina de Registro de documentos de la Arquidiócesis de Cali, 2016). 
Su profunda sensibilidad social le llevó a emprender obras colosales como el Banco de Alimentos, la Fundación Plan de Apoyo Familiar y Samaritanos de la Calle, que aún perduran en la ciudad de Cali, por medio de las cuales se otorga comida permanente a los habitantes de la calle (de la vega, O., 2016); “creó también programas contra el hambre: Samaritanos de la calle, el Banco de Alimentos, Ser Gente" (Cruz Hoyos, 2012).

Han pasado ya 15 años del asesinato de monseñor Isaías Duarte Cancino y aún no se conoce la verdad sobre los autores intelectuales de los hechos. En un principio las investigaciones señalaron a las FARC, pero luego los mismos jueces desvirtuaron las pruebas de esta acusación, dejando en el limbo total el esclarecimiento de los hechos que muchos analistas atribuyen a un complot entre políticos de la región y narcotraficantes, incomodos por la constante voz acusatoria del prelado, que siempre habló claro y de frente.

Hoy algunos de quienes lo conocieron, compartieron con Monseñor Isaías, recibieron y siguen recibiendo sus beneficios, conjugando el clamor de los pueblos por su palabra y sus obras, impulsan el proceso de su santificación. "Debe ser declarado inicialmente como mártir de la iglesia pues su vida plena es un testimonio de fe infalible en el evangelio de Cristo, vivió y murió predicando la palabra de su Dios y de su Iglesia, al igual que los primeros cristianos" (Montoya Flórez, 2016).

Por su parte, el actual párroco de la iglesia El Buen Pastor, donde Monseñor Isaías cayó abatido por las balas asesinas, promueve la creación allí de un santuario que eternice su vida, obra, pensamientos y enseñanzas" para que estas y todas las generaciones venideras beban de la fuente de su sacrificio, tengan presente su pasión y nunca más permitan que el país vuelva a trasegar por el camino espinoso de la guerra" (Paz O., Comunicación personal, 28 de agosto de 2016).

El hombre de blanco, sin miedo, el pastor que llevó la fe y la esperanza al corazón de los débiles y abandonados, la voz que como trueno retumbó en la conciencia de los extraviados, hoy vuelve convertida en el fuego de la paz. La voz callada abruptamente en el desierto de la violencia en Colombia, ratifica su presencia y vive hoy entre su pueblo, para convertir el desierto que le tocó trasegar, en fértil campo que da sombra y sustento a sus hijos e irradia a todos la luz de la esperanza de que otro mundo es posible.

\section{Discusión}

La necrobiografía, su definición y su ruta metodológica, se constituyen en un nuevo género periodístico que permite la elaboración de relatos biográficos de personajes fallecidos, contribuyendo al fortalecimiento de los géneros biográficos y aportando a las llamadas nuevas narrativas periodísticas. En concordancia con esto, Garza Acuña asegura que el periodismo se enfrenta a una serie de mutaciones o hibridaciones (2002), ya que actualmente se habla de una extrema alianza entre lo periodístico y lo literario, donde la necrobiografía hace parte de este mestizaje y aporta nuevos elementos para el mejor entendimiento del mundo, más allá de la estandarización o pragmatismo que se ha establecido en los grandes medios, donde prima lo inmediato, lo mercantil y lo superfluo (2002).

La necrobiografía no es una biografía simplemente, es más bien la biografía de un personaje fallecido, pues existen también biografías de personajes vivos; en contraposición a la biografía, que Pujadas (2000) ubica como un texto de género histórico-literario, la necrobiografía se ubica en el género periodístico, pues su escritura final se hace utilizando la estructura del reportaje, una modalidad textual, que si bien puede tener elementos literarios en su estilística, es estrictamente periodística. Pero si bien, hay una diferencia con los planteamientos de Pujadas, en lo relacionado con el género, hay unos encuentros con este autor en la búsqueda de la información para la elaboración del texto, pues ambos escritos (la biografía y la necrobiografía) van más allá de la recopilación de testimonios sobre el personaje objeto, y se pueden ubicar en el reflexivismo etnográfico, donde el periodista investigador asume una perspectiva etnográfica que lo convierte en mediador intercultural.

La ubicación de la necrobiografía en las nuevas narrativas periodísticas se hace desde el rescate de formas de relatar una historia, combinando elementos periodísticos y literarios, y no desde la perspectiva de las nuevas narrativas, desde la transmedia. En esta perspectiva se está en 
contravía de lo que expresan autores como Irala Hortal (2014), quien ubica únicamente las nuevas narrativas periodísticas en la transmedia

En comparación con las historias de vida, los relatos de vida, la biografía, la autobiografía, la semblanza y el perfil, la necrobiografía tiene como requisito indispensable la muerte del personaje, y en relación con la necrológica, va más allá de lo relacionado únicamente con la muerte.

La conceptualización de la necrobiografía, su metodología y su validación, utilizando la estructura del reportaje, son una contribución a la profundización de los estudios del periodismo biográfico, de los que asegura López (2002), cada día son más comunes en los diarios, pero sus estudios y manuales son escasos.

Por su parte, la validación de la necrobiografía, en el caso de Monseñor Isaías Duarte Cancino, permite explorar a este personaje más allá de los aspectos religiosos, propios de su investidura, y mostrar al hombre en toda su dimensión, con logros y dificultades, con dudas y con aciertos, con sus aspectos divinos pero también con los humanos, inserto entre la guerra y la paz, la esperanza y la desesperanza, la política y el evangelio. Lo anterior va en contraposición con quienes han escrito sobre Monseñor Isaías Duarte Cancino, como sucede con los dos libros de Montoya (2012, 2016), Isaías Duarte Cancino. Sangre de profeta e Isaías Duarte Cancino. Mártir de la Paz, que son una semblanza en la que se exalta la vida y obra del personaje acudiendo a constantes relaciones proféticas y religiosas. Otro de los autores que se sumerge en la vida de Monseñor Isaías Duarte Cancino es Echavarría (2012), pero lo hace desde un estilo de novela en verso, lo que le da una connotación de literatura religiosa, totalmente opuesta a la pretensión periodística académica de la necrobiografía.

En contraste, la validación de la necrobiografía en el relato de la muerte, la vida y el legado de este pastor de la Iglesia, es una narración escueta que reconstruye todos estos aspectos desde una mirada periodística investigativa.

\section{Referencias bibliográficas}

Arias Vega, E. (2007). Personajes de toda la vida. Centro Francisco Thoma y Valiente. -UNET Alzira.Valencia.

Arzobispo asesinado en Cali, Colombia. (18 de marzo de 2002). El País. Madrid. España. Arzobispo asesinado en Cali, Colombia. Recuperado el 13 de abril de 2017 de: https://elpais.com/diario/2002/03/18/internacional/1016406013 850215.htm

Asesinado Mons. Isaías Duarte Cancino, arzobispo de Cali. (2002). Roma: Revista Vitral . (Marzo-abril de 2002).. No. 48. Recuperado el 22 demarzo de 2017 de: $h \mathrm{ttp}: / /$ wwww.vitral.org/vitral48/nots.htm

BBC Mundo (18 de marzo de 2002). Colombia: tributo a arzobispo asesinado. Recuperado el 20 de marzo de 2017 de: http://news.bbc.co.uk/hi/spanish/latin americal newsid_1878000/1878059.stm

Bohórquez, C. (20 de marzo de 2002). Crimen no quedará impune. Bogotá: El Tiempo. Bogotá. Recuperado el 21 de febrero de 2017 de: http://www.eltiempo.com/ archivo/documento-2013/MAM-1343938

Caracol Radio (2017). Una bala por su costado derecho. Cali, Valle del Cauca. Recuperado el 19 de abril de 2017 de: http://caracol.com.co/emisora/2017/03/16/ cali/1489672823 932014.html

Cardenal Juan Luís. Cipriani. (17 de marzo de 2002). Arzobispado de Lima, Perú. Recuperado el 21 de abril de 2017 de: http://www.arzobispadodelima.org/hotas/2002/v_170302.htm

Cornejo, M., Mendoza, F. y Rojas, R. C. (2008). La Investigación con relatos de vida: pistas y opciones del diseño metodológico. Psykhe, 17, (1), 29-39. ISSN: 0718-2228. Recuperado el 19 de abril de 2017 de: http://www.scielo.cl/pdf/psykhe/v17n1/art04.pdf

Cruz Hoyos, S. (2012). Este es el legado de Monseñor Isaías Duarte Cancino. Periódico El País. Cali. Marzo 11.

Echavarría Pulido, J (2012). El llano canta a la paz. Volumen II. Bogotá: Editorial Kimpres Ltda. Bogotá. 
Fue el amigo que puso la cara. (18 de marzo2002). El Tiempo. (2002). Recuperado el 20 de febrero de 2017 de: http://www.eltiempo.com/archivo/documento/MAM-1347988

Fundación Isaías Duarte Cancino. Colombia, viva, libre y en paz. Recuperado el 10 de marzo de 2017 de: http://www.isaiasduarte.org/

Garza Acuña, C. J. (2002). Vigencia del relato como sentido de la realidad: Análisis de reportajes históricos. Universidad Complutense de Madrid. Facultad de Ciencias de la Información. Departamento de Periodismo. Tesis Doctoral. Madrid, p. 578 .

Irala Hortal, P. (2014). Nuevas narrativas en el periodismo actual. El Periodismo Transmediático. Estudios sobre el Mensaje Periodístico. 20, (1) (enero-junio), p,. 147-158. Madrid, Servicio de Publicaciones de la Universidad Complutense. Madrid.

López Hidalgo, A. (1999). La necrológica, como género periodístico. Revista Latina de Comunicación Social., 15. Recuperado el 21 de abril de 2017 de: http://www.ull.es/publicaciones/latinal a1999c/114lopez.htm.

López Hidalgo, A. (2002). La historia de vida periodística, un género poco usual en la prensa española. Revista Latina de Comunicación Social., 47. Recuerado el 15 de septiembre de 2017 de: http://www.ull.es/publicaciones/latina/2002/latina47febrero/4702lopez.htm

Martín García, V. (1995). Fundamentación teórica y uso de las historias de vida como técnicas de investigación en pedagogía social. Facultad de Educación. Universidad de Salamanca. ISSN: 0214-234 . p. 41-60.

Montoya Flórez, E. (2012). Isaías Duarte Cancino. Sangre de profeta. 1 ed. Bogotá: Instituto Misionero Hijas de San Pablo. Bogotá. Primera edición.

Montoya Flórez, E. (2016). Isaías Duarte Cancino. Mártir de la paz. 1 ed. Instituto Misionero Hijas de San Pablo. Bogotá.Primera edición.
Moreno Hernández, D. (2005). Relatoría de taller de perfiles con Jon Lee Anderson. Fundación Nuevo Periodismo Iberoamericano (FNPI). Buenos Aires, 5-9 de diciembre de 2005. Recuperado el 18 de amrzo de 2017 de: https://es.scribd.com/doc/19476581/EL-ARTEDE-DIBUJAR-CON-PALABRAS-A-UNA-PERSONA.

Nulivalue, T. (2002). Asesinado Monseñor Duarte C. El Tiempo. Bogotá. Recuperado de el 19 de abril de 2017 de: http://www.eltiempo.com/archivo/documento/ MAM-1350338.

Parroquias creadas periodo Monseñor Isaías Duarte Cancino 1995 - 2002. Documentos, Oficina de Registro de la Arquidiócesis de Cali. Consultados de 2016.

Periodismo Narrativo: La semblanza. (s. f.). Recuperado 24 de julio de 2018, de http://periodimonarrativo.blogspot. com/2011/09/la-semblanza.html

Pujadas, J. J. (2000). El método biográfico y los géneros de la memoria. Revista de Antropología Social . Universidad Rovira iVirgili. 9, p. 127-158.

Restrepo, M. A. R. (2011, marzo 1). MIGUEL ÁNGEL RÍOS: EL PERFIL: El arte de pintar con palabras a una persona. Recuperado 24 de julio de 2018, de http://blogmiguelclases.blogspot.com/2011/03/el-perfilel-arte-de-pintar-con.html-2005. Universidad de Zaragoza.

Rosendo, Belén. (1997). El perfil como género periodístico. Revista Comunicación y Sociedad. Universidad de Navarra, España. 10. (1). Recuperado de: http://dadun. unav.edu/bitstream/10171/8672/1/20091106225918.pdf.

Sanz Hernández, M. A. (2005). El método biográfico en investigación social: Ppotencialidades y limitaciones de las fuentes orales y los documentos personales. Asclepio. -Vol. LVII, -1.

ZENIT.org. Colombia se despide de su obispo asesinado (20 de marzo de 2002). Colombia se despide de su obispo asesinado . El Vaticano. Recuperado el 29 de abril de 2017 de: https://es.zenit.org/articles/colombia-se-despide-de-su-arzobispo-asesinado/ 